\title{
PRESENT STATUS OF THE PERSONAL NEUTRON DOSEMETER BASED ON DIRECT ION STORAGE
}

\author{
A. Fiechtner*, M. Boschung and C. Wernli \\ Paul Scherrer Institut, CH-5232 Villigen PSI, Switzerland
}

\begin{abstract}
In this paper the present status of the Direct Ion Storage Neutron (DIS-N) prototype dosemeter (RADOS) is described. The separation of neutron from photon dose equivalent has been improved by adding tin shieldings. The neutron energy response has been changed by additional plastic covers containing $40 \% \mathrm{~B}_{4} \mathrm{C}$ in order to reduce the over-response to thermal neutrons. The responses of the dosemeters were determined for standard photon and neutron fields (monoenergetic neutrons, neutron sources and simulated workplace fields). Irradiations in real workplaces were also performed. The dependence of the neutron response on the angle of incidence was measured for different neutron sources.
\end{abstract}

\section{DESIGN OF IMPROVED DIS-N DOSEMETER}

The personal neutron dosemeter DIS-N (Figure 1), produced by RADOS Technology Oy, is based on ionisation chambers with direct ion storage and a double-chamber system that allows differential readings to separate the neutron from the photon dose equivalent ${ }^{(1)}$. The photon energy response of the two chambers of former DIS-N prototypes was significantly different in the photon energy region below $100 \mathrm{keV}$, which could have led to a false determination of the personal neutron dose equivalent. The situation has been improved by adding in all dosemeter types a 1-mm-thick tin shielding around the chambers to cut off photon energies below $100 \mathrm{keV}$.

Furthermore, former designs tended to an overresponse to thermal neutrons, which can be reduced by surrounding the dosemeter with plastic 'boroncovers' containing $40 \% \mathrm{~B}_{4} \mathrm{C}$. Four types of dosemeter (Table 1) were built and tested under different circumstances. The wall materials of the neutron/ photon sensitive chambers are made of A-150 containing $1.25 \%$ boron nitride (BN) or polyethylene (PE) containing $4 \% \mathrm{LiNO}_{3}$. The photon-sensitive chambers were in all cases made of Teflon (polytetraflouroethylene) containing $60 \%$ graphite. The size of a dosemeter is $45 \times 45 \times 15 \mathrm{~mm}^{3}$, and the weight is about $56 \mathrm{~g}$. The readout of the dosemeter is performed with a table-top unit (DBR-1).

\section{IRRADIATION CONDITIONS}

The dosemeters were mounted for all irradiations on the ISO water-slab-phantom of size $30 \times 30 \times 15 \mathrm{~cm}^{3}$. The distance to the radiation source was measured from the front plane of the phantom and varied between 0.5 and $1 \mathrm{~m}$.

*Corresponding author: annette.fiechtner@psi.ch

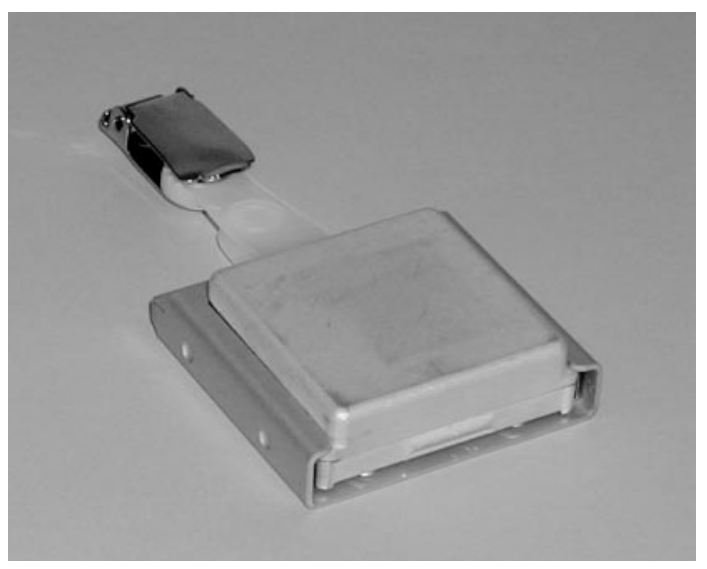

Figure 1. DIS-N dosemeter.

\section{ENERGY DEPENDENCE OF PHOTON RESPONSE}

The energy dependence of the photon response was determined at the calibration laboratory of the Paul Scherrer Institut between 24 and $660 \mathrm{keV}$ at normal incidence. Typical results for the neutron/photonsensitive chamber and the photon-sensitive chamber of the $\mathrm{PE}\left(4 \% \mathrm{LiNO}_{3}\right)$ dosemeter are shown in Figure 2. Due to the tin shielding, photon energies lower than $100 \mathrm{keV}$ may be neglected. Thus the energy dependences of the photon response are very similar, and the separation of neutron from photon dose equivalent is improved in mixed neutron/ photon fields.

\section{ENERGY DEPENDENCE OF NEUTRON RESPONSE}

The energy dependence of the personal neutron dose equivalent response, shown in Table 2 and Figure 3, 


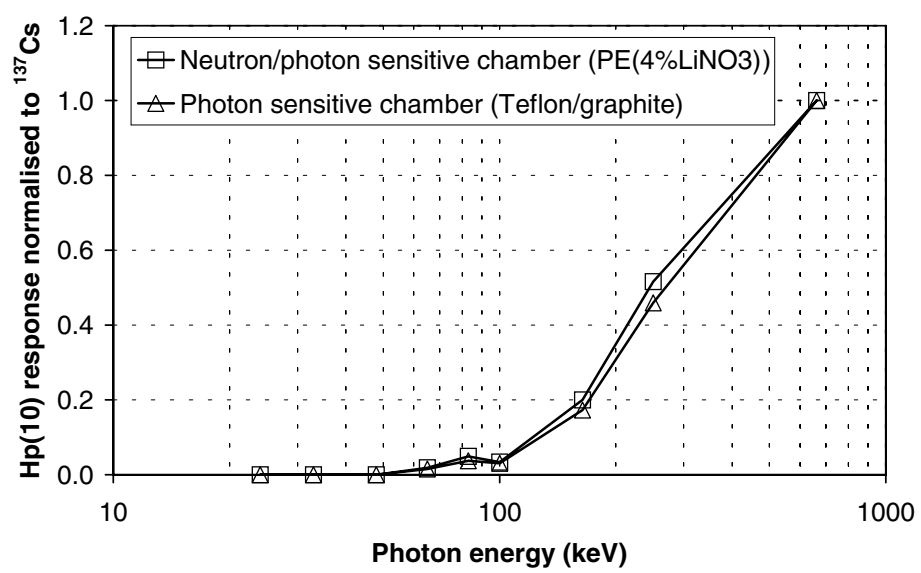

Figure 2. Energy dependence of the $H_{\mathrm{p}}(10)$ photon responses of the neutron/photon-sensitive chamber $\mathrm{PE}(4 \% \mathrm{LiNO})$ and the photon-sensitive chamber Teflon/graphite with an integrated $1 \mathrm{~mm}$ tin shielding.

Table 1. Description of DIS-N dosemeter design.

\begin{tabular}{|c|c|c|c|}
\hline Dosemeter type & $\begin{array}{c}\text { Wall material of } \\
\text { photon-sensitive chamber }\end{array}$ & $\begin{array}{l}\text { Wall material of neutron/ } \\
\text { photon-sensitive chamber }\end{array}$ & Additional cover \\
\hline $\mathrm{PE}\left(4 \% \mathrm{LiNO}_{3}\right)$ & Teflon/graphite & $\mathrm{PE}+4 \% \mathrm{LiNO}_{3}$ & - \\
\hline $\mathrm{PE}\left(4 \% \mathrm{LiNO}_{3}\right)\left(1 \mathrm{~mm} \mathrm{~B}{ }_{4} \mathrm{C}\right)$ & Teflon/graphite & $\mathrm{PE}+4 \% \mathrm{LiNO}_{3}$ & $1 \mathrm{~mm} \mathrm{~B}_{4} \mathrm{C}$ \\
\hline $\mathrm{A}-150(1.25 \% \mathrm{BN})$ & Teflon/graphite & $\mathrm{A}-150+1.25 \% \mathrm{BN}$ & - \\
\hline A-150 (1.25\% BN) $\left(2 \mathrm{~mm} \mathrm{~B}_{4} \mathrm{C}\right)$ & Teflon/graphite & $\mathrm{A}-150+1.25 \% \mathrm{BN}$ & $2 \mathrm{~mm} \mathrm{~B}_{4} \mathrm{C}$ \\
\hline
\end{tabular}

Table 2. $H_{\mathrm{p}}(10)$ neutron responses of four different dosemeter types to monoenergetic neutrons, neutron sources and simulated workplace field spectra, normalised to ${ }^{241}$ AmBe.

\begin{tabular}{|c|c|c|c|c|}
\hline $\begin{array}{l}\text { Neutron energy } \\
(\mathrm{MeV}) / \text { neutron } \\
\text { source/field spectra }\end{array}$ & $\begin{array}{c}\mathrm{PE} \\
\left(4 \% \mathrm{LiNO}_{3}\right)\end{array}$ & $\begin{array}{c}\mathrm{PE} \\
\left(4 \% \mathrm{LiNO}_{3}\right) \\
\left(1 \mathrm{~mm} \mathrm{~B} \mathrm{~B}_{4} \mathrm{C}\right)\end{array}$ & $\begin{array}{c}\mathrm{A}-150 \\
(1.25 \% \mathrm{BN})\end{array}$ & $\begin{array}{c}\mathrm{A}-150 \\
(1.25 \% \mathrm{BN}) \\
\left(2 \mathrm{~mm} \mathrm{~B} \mathrm{~B}_{4} \mathrm{C}\right)\end{array}$ \\
\hline $2.53 \mathrm{E}-08$ & $12 \pm 3$ & $1.0 \pm 0.2$ & $50 \pm 15$ & $2.3 \pm 0.7$ \\
\hline Sigma & $4.2 \pm 0.5$ & $1.0 \pm 0.1$ & $21 \pm 3$ & $1.1 \pm 0.2$ \\
\hline Canel & $2.5 \pm 0.5$ & $0.54 \pm 0.11$ & $7.9 \pm 1.6$ & $0.64 \pm 0.13$ \\
\hline 0.070 & $0.45 \pm 0.13$ & $0.17 \pm 0.06$ & $1.7 \pm 0.2$ & $0.14 \pm 0.06$ \\
\hline 0.144 & $0.26 \pm 0.04$ & $0.14 \pm 0.03$ & $0.74 \pm 0.09$ & $0.19 \pm 0.03$ \\
\hline 0.565 & $0.48 \pm 0.06$ & $0.36 \pm 0.06$ & $0.63 \pm 0.08$ & $0.47 \pm 0.08$ \\
\hline $\mathrm{Cf}^{252}\left(\mathrm{D}_{2} \mathrm{O}\right)$ & $0.92 \pm 0.09$ & $0.70 \pm 0.07$ & $2.2 \pm 0.2$ & $0.97 \pm 0.10$ \\
\hline $\mathrm{Cf}^{252}\left(\mathrm{D}_{2} \mathrm{O}\right), \mathrm{Cd}$ & $0.89 \pm 0.09$ & $0.71 \pm 0.07$ & $1.6 \pm 0.2$ & $0.85 \pm 0.09$ \\
\hline $\mathrm{Cf}^{252}$ & $0.88 \pm 0.09$ & $0.70 \pm 0.07$ & $0.90 \pm 0.09$ & $0.83 \pm 0.08$ \\
\hline${ }^{241} \mathrm{AmBe}$ & $1.0 \pm 0.1$ & $1.0 \pm 0.1$ & $1.0 \pm 0.1$ & $1.0 \pm 0.1$ \\
\hline 14.8 & $0.78 \pm 0.09$ & $0.78 \pm 0.09$ & $0.75 \pm 0.09$ & $0.76 \pm 0.09$ \\
\hline CERF concrete & - & $0.42 \pm 0.05$ & $0.80 \pm 0.10$ & - \\
\hline
\end{tabular}

was measured for all dosemeter types for monoenergetic neutrons from thermal energies up to $14.8 \mathrm{MeV}$, for neutron sources and for simulated workplace field spectra. Irradiations with thermal neutrons were performed at the thermal beam at $\mathrm{GKSS}^{(2)}$ (Geesthacht, Germany). Irradiations with monoenergetic neutron energies were performed at the PTB (Braunschweig, Germany). Two simulated workplace field spectra were supplied by IRSN (Cadarache, France). These were a broad, partly thermalised neutron spectrum, 'Canel'(3), and a highly thermalised neutron spectrum, 'Sigma'(4). 


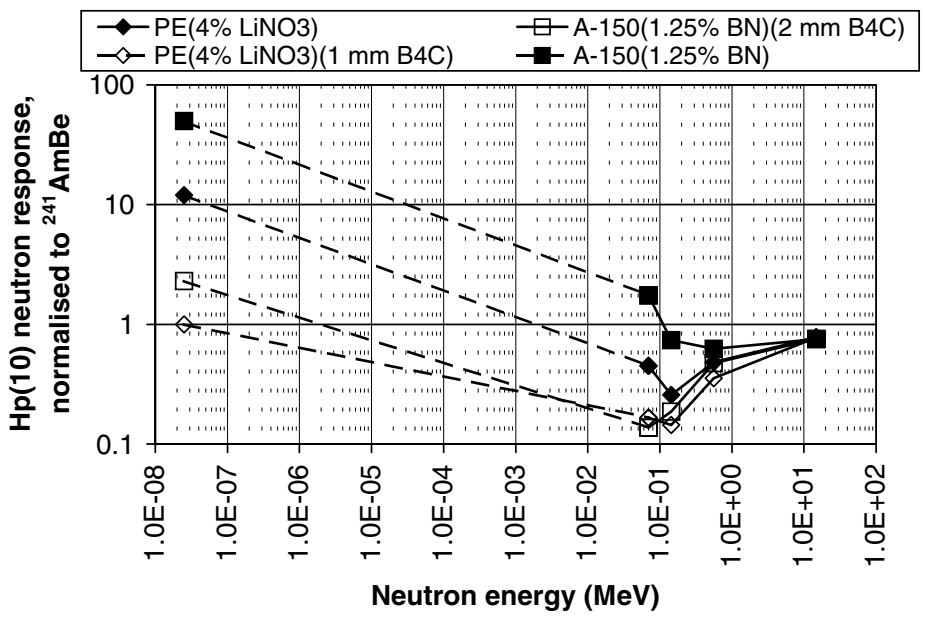

Figure 3. Energy dependence of the $H_{\mathrm{p}}(10)$ neutron responses of four different dosemeter types to monoenergetic neutrons, normalised to ${ }^{241} \mathrm{AmBe}$.

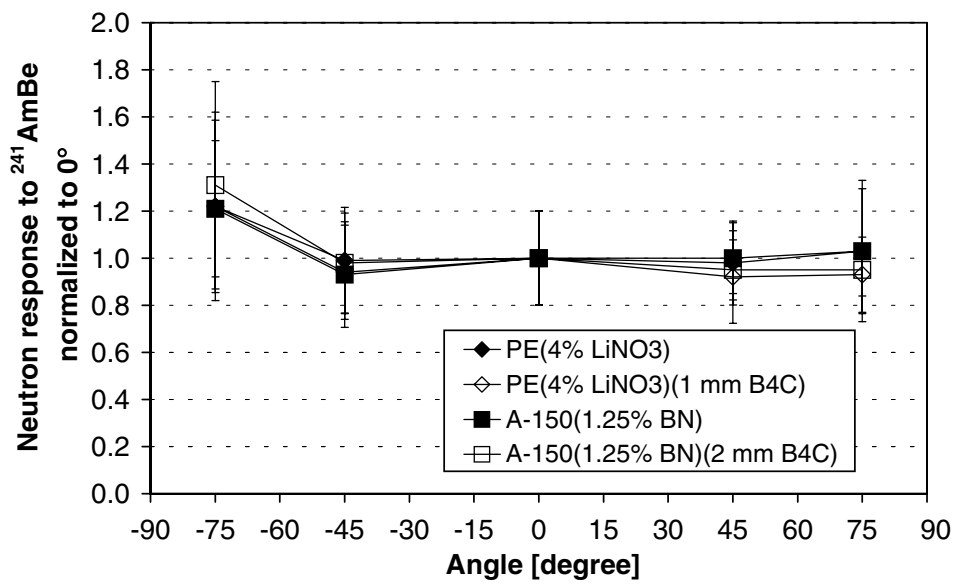

Figure 4. $H_{\mathrm{p}}(10)$ neutron responses to ${ }^{241} \mathrm{AmBe}$ as a function of the angle of incidence to the vertical axis of four different dosemeter types.

Measurements were also performed in a high neutron energy field at the CERN reference radiation facility $(\mathrm{CERF})^{(5,6)}$. The neutron responses to the intermediate neutron energy region (Figure 3) have not yet been determined, and therefore the dashed lines between $2.5 \times 10^{-8}$ and $0.07 \mathrm{MeV}$ are only a guideline. The responses will be determined using a deconvolution method that is described elsewhere ${ }^{(7)}$.

The dosemeter types $\mathrm{PE}\left(4 \% \mathrm{LiNO}_{3}\right)$ and $\mathrm{A}-150$ $(1.25 \% \mathrm{BN})$, without a boron-cover, have a relatively flat response to neutron energies from $70 \mathrm{keV}$ up to $14.8 \mathrm{MeV}$ and to neutron sources but have a significant over-response to thermal neutrons and to thermalised neutron spectra, especially the A-150 $(1.25 \% \mathrm{BN})$ dosemeter. The boron covers of the dosemeter types PE $\left(4 \% \mathrm{LiNO}_{3}\right)\left(1 \mathrm{~mm} \mathrm{~B}_{4} \mathrm{C}\right)$ and $\mathrm{A}-150$
$(1.25 \% \mathrm{BN})\left(2 \mathrm{~mm} \mathrm{~B} \mathrm{~B}_{4} \mathrm{C}\right)$ extenuate this effect. Nevertheless, an under-response to neutron energies in the kiloelectronvolt-region (minimum at $144 \mathrm{keV}$ ) and also to the intermediate neutron energy region was observed with these dosemeter types.

\section{ANGLE DEPENDENCE OF THE NEUTRON RESPONSE}

The angle dependence of the neutron response was measured at the Paul Scherrer Institut at angles of incidence of $-75^{\circ},-45^{\circ}, 0^{\circ},+45^{\circ}$ and $+75^{\circ}$ (vertical axis) for the ${ }^{241} \mathrm{Am}-\mathrm{Be}$ and ${ }^{252} \mathrm{Cf}\left(\mathrm{D}_{2} \mathrm{O}\right.$, $\mathrm{Cd}$ ) neutron sources. The results are presented in Figures 4 and 5 . Below $45^{\circ}$, the relative neutron response changes less than $40 \%$. At an angle of 


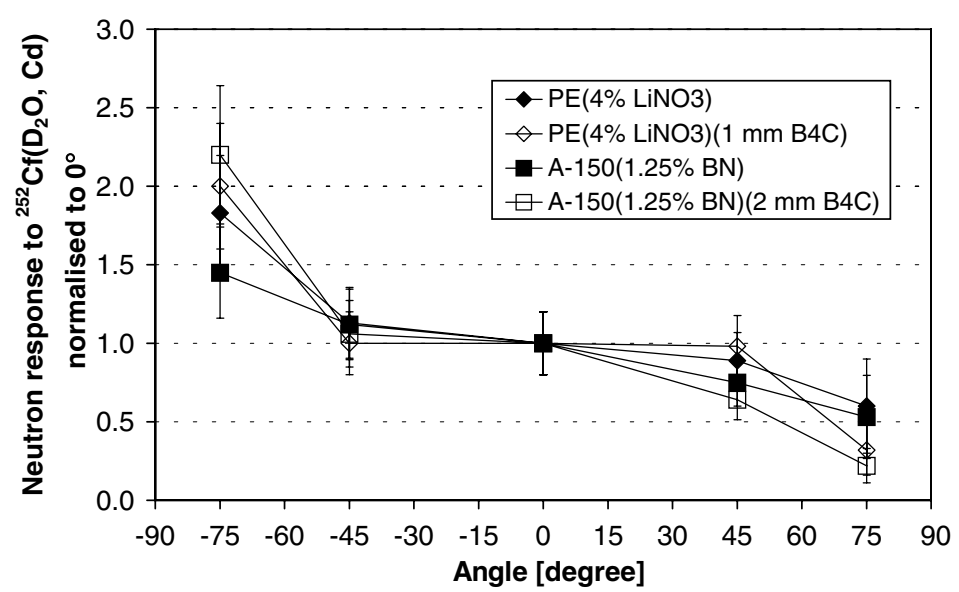

Figure 5. $H_{\mathrm{p}}(10)$ neutron responses to ${ }^{252} \mathrm{Cf}\left(\mathrm{D}_{2} \mathrm{O}, \mathrm{Cd}\right)$ as a function of the angle of incidence to the vertical axis of four different dosemeter types.

Table 3. Preliminary results of the first measurement campaign in real workplaces at the nuclear power plant Krümmel in Germany.

\begin{tabular}{lccc}
\hline Measurement point & $\mathrm{PE}\left(4 \% \mathrm{LiNO}_{3}\right)$ & $\mathrm{A}-150(1.25 \% \mathrm{BN})$ & $\begin{array}{c}\mathrm{LB} 6411 \\
\end{array}$ \\
\hline Cask midline & $\left(1 \mathrm{~mm} \mathrm{~B} \mathrm{C}_{4} H_{\mathrm{p}}(10)_{n}\left(\mu \mathrm{Sv} \mathrm{h}{ }^{-1}\right)\right.$ & $\left(2 \mathrm{~mm} \mathrm{~B} \mathrm{C}_{4} H_{\mathrm{p}}(10)_{n}(\mu \mathrm{Sv} \mathrm{h})^{-1}\right)$ & $H^{*}(10)_{n}\left(\mu \mathrm{Sv} \mathrm{h}^{-1}\right)$ \\
Cask side & $12 \pm 10$ & $63 \pm 20$ & $140 \pm 30$ \\
SAR, boiling reactor & $*$ & $13 \pm 6$ & $50 \pm 10$ \\
Top, boiling reactor & $15 \pm 15$ & $*$ & $60 \pm 12$ \\
\hline
\end{tabular}

*Below detection limit.

$\pm 75^{\circ}$ the response changes asymmetrically between 0.2 and 2.5 , depending on the spectrum/neutron energy. For spectra with a large number of fast neutrons, like ${ }^{241} \mathrm{AmBe}$, the angle dependence of the neutron response is much less pronounced than for spectra with more thermalised neutrons, like ${ }^{252} \mathrm{Cf}\left(\mathrm{D}_{2} \mathrm{O}, \mathrm{Cd}\right)$. The asymmetry of the angle dependence is caused by the geometrical configuration of the neutron/photon-sensitive chamber and the photon-sensitive chamber inside the dosemeter, where one chamber shields the other chamber for an extreme angle like $75^{\circ}$.

\section{FIELD EXPERIMENTS}

Within the project EVIDOS ('Evaluation of individual dosimetry in mixed neutron and photon radiation fields'), which is funded by the EC within the 5th framework, measurement campaigns at real workplaces were and will be performed. The first measurement campaign was carried out at a boiling water reactor and at a storage cask with used fuel elements at the nuclear power plant Krümmel in
Germany. The determination of reference values for the personal dose equivalent is described elsewhere ${ }^{(8)}$. The neutron energy spectra have in general a distribution in the lower kiloelectronvolts and intermediate energy region. For the irradiations, only dosemeters with boron covers were used [PE $\left(4 \% \mathrm{LiNO}_{3}\right)\left(1 \mathrm{~mm} \mathrm{~B} \mathrm{~B}_{4} \mathrm{C}\right)$ and $\mathrm{A}-150(1.25 \% \mathrm{BN})$ $\left.\left(2 \mathrm{~mm} \mathrm{~B}_{4} \mathrm{C}\right)\right]$. The measured personal neutron dose equivalent rates are compared with preliminary dose rates of an area monitor (LB6411) (Table 3). For the measurement point 'SAR, boiling reactor' the ratio of the personal photon dose equivalent to the personal neutron dose equivalent is about 3 , which is at the present development status of the dosemeter too high for the measurement of a neutron dose. At the measurement point 'Top, boiling reactor', the irradiation time was too short, and measured doses were partly below the detection limit. The results indicate that these dosemeter types are not suitable for neutron spectra with a high proportion of intermediate neutron energies because the response to these energies is too low and correspondingly the detection limit would be too high. 


\section{CONCLUSIONS}

The experiments did not indicate if the use of boron covers (surrounding the dosemeter) is recommendable. A second measurement campaign within EVIDOS was carried out at the research reactor VENUS at CEN/SCK, and the fuel processing plant of Belgonucleaire in Belgium, where most neutrons are high-energy neutrons or are only partly thermalised. The preliminary results showed that the PE (4\% $\left.\mathrm{LiNO}_{3}\right)$ dosemeter without a boron cover could be a useful compromise for broad neutron energy spectra as long as it is not used in highly thermalised neutron spectra. Which type of dosemeter is optimal depends, therefore, on the field of application.

The construction of a dosemeter that is only covered on the front side with a boron cover (similar to the principle of an albedo dosemeter) should be considered, to maintain a high enough sensitivity to intermediate neutrons along with a reasonable response to thermal neutrons.

Apart from the discussion regarding which type of dosemeter is useful for which type of spectrum, all dosemeter types still have the drawback that they are only usable in mixed photon/neutron fields as long as the personal photon dose equivalent is not greater than twice the personal neutron dose equivalent. Otherwise the detection limit of the personal neutron dose equivalent exceeds $100 \mu \mathrm{Sv}$.

\section{ACKNOWLEDGEMENTS}

Special thanks to Marlies Luszik-Bhadra for fruitful discussions and to the staff of the GKSS facility for their assistance during the measurements. This work was partly performed within the European Commission RTD Programme, Nuclear Energy, Euratom Framework Programme V, 1998-2002, Contract
No. FIKR-CT-2001-00175, and was funded partly by the Federal Office of Education and Science (BBW contract No. 01.0024).

\section{REFERENCES}

1. Fiechtner, A., Wernli, C. and Kahilainen, J. A prototype personal neutron dosemeter based on an ion chamber and direct ion storage. Radiat. Prot. Dosim. 96(1-3), 269-272 (2001).

2. Böttger, R., Dietz, E., Friedrich, H., Lagner, F., Luszik-Bhadra, M. and Sosaat, W. Thermal neutron calibration field for radiation protection. GKSS report 2002/4 (2002).

3. Lacoste, V., Gressier, V. and Bolognese-Milsztajn, T. Monte-Carlo simulation of the neutron and dosimetric characteristics at the IRSN Canel/T400 facility. Radiat. Prot. Dosim. 110(1-4), 123-127 (2004).

4. Muller, H., Gressier, V., Lacoste, V., Lebreton, L. and Pochat, J.-L. Characterization of the thermal neutron field produced by the IRSN sigma facility. Radiat. Prot. Dosim. 110(1-4), 136-140 (2004).

5. Schuhmacher, H., Brede, H. J., Dangendorf, V. and Kuhfuss, M. Quasi-monoenergetic neutron beams with energies from 25 to $70 \mathrm{MeV}$. Nucl. Instrum. Meth. Phys. Res. A 421, 284-295 (1999).

6. Birattari, C., Ferrari, A., Höfert, M., Otto, T., Rancati, T. and Silari, M. Recent Results at the CERN-EC High Energy Reference Field Facility. Third Specialists' Meeting on Shielding Aspects of Accelerators, Targets and Irradiation Facilities, Sendai, Japan, 12-13 May 1997 (Paris: OECD) pp. 219-234 (1998).

7. Reginatto, M. et al. Dose equivalent response of neutron dosemeters determined using unfolding methods. Presented at the Eleventh International Congress of the International Radiation Protection Association, Madrid, Spain, 23-28 May 2004.

8. Luszik-Bhadra, M. et al. EVIDOS: evaluation of individual monitoring in mixed neutron/photon fields at workplaces in the nuclear fuel cycle. Presented at the Fourth EC/IAEA/ISOE Workshop on Occupational Exposure Management at NPP's, Lyon, France, 24-26 March (2004). 